\title{
Are Obese Plant Genomes on a Diet?
}

\author{
Pablo D. Rabinowicz ${ }^{1}$ \\ Cold Spring Harbor Laboratory, Cold Spring Harbor, New York 11724 USA
}

$\mathbf{R}$ ichard Dawkins' (1976) selfish DNA hypothesis (that the only purpose of DNA is to perpetuate itself) is clearly reflected in the case of repetitive DNA, especially retrotransposons. These ubiquitous, self-replicating DNA elements do not seem to do anything but invade the host's genome (Orgel and Crick 1980; Doolittle and Sapienza 1980). Mutations caused by the activity of retrotransposons may eventually be evolutionarily advantageous, but are more likely to be deleterious for the host organism and thus eliminated from the population (Charlesworth et al. 1994). However, insertions of those elements that do not alter any functional region of the genome may be perpetuated in the population.

In this scenario, differences in retrotransposon activity leading to the accumulation of multiple repeats of these elements can easily explain the large differences in genome size observed even among related organisms. The observation that a large genome is not correlated with the complexity of the organism is known as the C-value paradox (Thomas 1971). Amplification of mobile elements would be limited by loss of host fitness due to their deleterious effects, but at least in some species, other mechanisms for preventing retrotransposon activity must exist to explain differences in the amount of repetitive DNA. DNA methylation has been proposed to be one such mechanism (Martienssen 1998), although other mechanisms may exist in organisms that lack methylation.

Introducing a different perspective, Petrov et al. (1996) showed that there is not only limitation of transposon prolif-

\footnotetext{
1E-MAIL rabinowi@cshl.org; FAX (516) 367 8369.
}

eration, but also deletion of repetitive DNA: In the unmethylated genome of Drosophila, non-LTR retrotransposon DNA is lost 25 times faster than in mammals. In recent work, Petrov et al. (2000) used the same analysis to compare the DNA loss rate in Drosophila and another insect genus, Laupala (crickets), whose genome is about 11 times bigger than that of Drosophila. The authors found that the rate of DNA loss in crickets is about 40 times slower than in Drosophila. On the other hand, Charlesworth (1996) argued that in cases of vast amounts of repetitive DNA (which is often LTR-retrotransposons), the amount of DNA loss due to small, non-LTR retrotransposon deletions would not be significant.

Until the recent identification of a possible DNA deletion mechanism in barley (Vicient et al. 1999; Shirasu et al. 2000), there has been no example of repetitive DNA loss in plants, although there is a 1000-fold genome size variation among species (Bennet and Leitch 1995). This led Bennetzen and Kellogg (1997) to analyze the evolution of grass genome sizes under two models: one assuming that genomes can only increase in size, and another allowing both increases and decreases. Under either model, they concluded that there has been a steady increase in genome size during the evolution of the grass family. Although Bennetzen and Kellogg disagreed on the probability of finding a mechanism for excising repetitive DNA, they concluded that in any case, plants have a "one-way ticket to genomic obesity." The return ticket was provided later by Vicient et al. (1999) who observed up to a 42-fold excess of LTRs relative to internal domains of the $B A R E$-1 LTR-retrotransposon in barley (by hybridizing LTR or internal domains to different species of the genus Hordeum). Furthermore, the authors found that the larger the proportion of LTRs relative to intact $B A R E-1$ elements, the smaller the total fraction of the genome occupied by BARE-1. These observations could be explained by intra- or interelement homologous recombination between BARE-1 LTRs. Such a mechanism would produce more significant repetitive DNA elimination than the deletions of non-LTR elements observed in Drosophila.

In this issue, Shirasu et al. (2000) supply sequence data to support this hypothesis. In a $66 \mathrm{~kb}$ contiguous sequence at the Rar1 locus from barley chromosome $2 \mathrm{HL}$, they found three genes flanked by complex arrays of retrotransposons. In addition to the abundant BARE-1 element, four novel LTR retrotransposons are described (Nikita, Sukkula, Sabrina, andBAGY-2). As observed in maize (SanMiguel et al. 1996), the barley retroelements are arranged in nested insertions. Confirming previous observations in barley (Vicient et al. 1999), most of the elements are present as solo LTRs [unlike maize, where solo LTRs are rare (SanMiguel et al. 1996)]. A detailed analysis of the sequence revealed that at least four of the five $B A R E-1$ elements found have undergone intra- or inter-element recombination mediated by their LTRs, leading to loss of internal domains. Two BARE-1 solo LTRs were probably the result of internal recombination, while two other LTRs, each containing a small chunk of the internal part of the element, might have arisen by insertion of one element into the other and by subsequent recombination between one LTR from each element. Among the other retroelements identified in the studied region, a significant proportion seems to be solo 
LTRs, although accurate annotation of these novel elements is more difficult.

These results strongly suggest that recombination between LTRs is an efficient way to counteract transposon expansion, at least among certain grasses. It is still not clear how significant this process may be in other plants. The authors propose that it may depend on the length of an element's LTRs: The longer the LTR, the more likely the element will undergo recombination. This is supported by the situation found in maize, where most of the retrotransposon LTRs are shorter than those of barley $(<0.7 \mathrm{~kb}$ versus $\simeq 2 \mathrm{~kb}$, respectively). This length difference might explain the observed low proportion of maize solo LTRs. Furthermore, the only solo LTR elements found in maize are among the longest (>1 kb).

However, if it is just the presence of long LTRs that allows the excision of repeats, only plants whose retrotransposons have such LTRs will be able to reduce their repetitive DNA content. In addition, there would be selection pressure favoring retrotransposons with short LTRs, which could not be easily eliminated by this mechanism. One can speculate that rather than LTR length, it is the large genome size of barley $(4-5 \times$ $10^{9} \mathrm{bp}$ ) that triggers the excision mechanism. In this scenario, there would be a way to sense the repeats/genes ratio. When this ratio exceeds a certain threshold, LTR-targeted recombination machinery would be activated. Consid- ering that maize is a segmental allotetraploid (Gaut and Doebley 1997), each maize subgenome $\left(1.5 \times 10^{9} \mathrm{bp}\right)$ might still be too small to activate such a mechanism.

If there is such a genome size threshold to trigger antiretrotransposon activity, an interesting question that arises is whether the process would stop when the genome size returns below threshold or continue to reduce it even further. Alternatively, a more stochastic model can be hypothesized in which, as the number of repeats becomes larger, the deletion process occurs more frequently.

Under either model, it would be expected that large diploid genomes contain large proportions of solo LTRs. The threshold model also allows the possibility of finding relatively small genomes with a large proportion of solo LTRs relative to intact elements. Extensive sequence analyses of grasses with larger genomes, like wheat or rye ( $\simeq 6$ and $9 \times$ $10^{9} \mathrm{bp}$, respectively), will certainly shed more light on this and other possible mechanisms affecting genome size variation. In the same way, detailed analysis of the growing amount of rice sequence data will help us understand why rice and other grasses have small genomes $\left(4 \times 10^{8}\right)$, adding new elements to the explanation of Thomas' Cvalue paradox.

\section{ACKNOWLEDGMENTS}

I thank Erik Vollbrecht, Rob Martiens- sen, Mary Byrne, and Bruce May for significant comments on the manuscript.

\section{REFERENCES}

Bennet, M.D. and Leitch, I.J. 1995. Ann. Bot. 76: $113-176$.

Bennetzen, J.L. and Kellogg, E.A. 1997. The Plant Cell 9: 1509-1514.

Charlesworth, B. 1996. Nature 384: 315-316.

Charlesworth, B., Sniegowski, P., and Stephan, W. 1994. Nature 371: 215-220.

Dawkins, R. 1976. The Selfish Gene. Oxford University Press, New York.

Doolittle, W.F. and Sapienza, C. 1980. Nature 284: 601-603.

Gaut, B.S. and Doebley, J.F. 1997. Proc. Natl. Acad. Sci. USA. 94: 6809-6814.

Martienssen, R.A. 1998. Trends Genet. 14: 263-264.

Orgel, L.E. and Crick, F.H.C. 1980. Nature 284: 604-607.

Petrov, D.A., Lozovskaya, E.R., and Hartl, D.L. 1996. Nature 384: 346-349.

Petrov, D.A., Sangster, T.A., Johnston, J.S., Hartl, D.L., and Shaw, K.L. 2000. Science 287: 1060-1062.

SanMiguel, P., Tikhonov, A., Jin, Y.K., Motchoulskaia, N., Zakharov, D., Melake-Berhan, A., Springer, P., Edwards, K.J., Lee, M., Avramova, Z., and Bennetzen, J.L. 1996. Science 274: 765-768.

Shirasu, K., Schulman, A.H., Lahaye, T., and Schulze-Lefert, P. 2000. Genome Res. (this issue)

Thomas, C.A. 1971. Annu. Rev. Genet. 5: 237-256.

Vicient, C.M., Suoniemi, A., Anamthawat-Jónsson, K., Tanskanen, J., Beharav, A., Nevo, E., and Schulman, A.H. 1999. The Plant Cell 11: 1769-1784. 


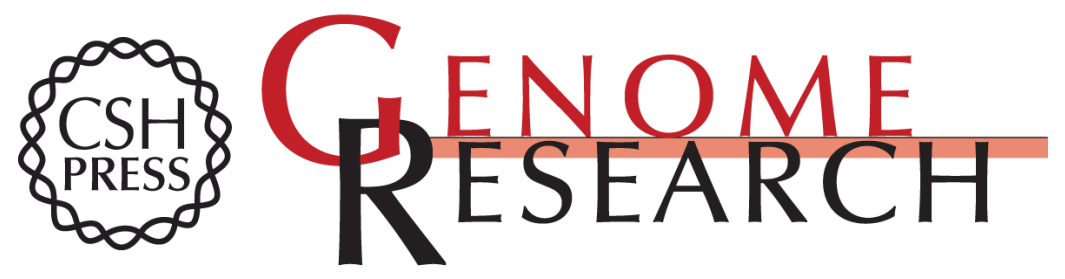

\section{Are Obese Plant Genomes on a Diet?}

Pablo D. Rabinowicz

Genome Res. 2000 10: 893-894

Access the most recent version at doi:10.1101/gr.10.7.893

References This article cites 13 articles, 5 of which can be accessed free at: http://genome.cshlp.org/content/10/7/893.full.html\#ref-list-1

\section{License}

Email Alerting Receive free email alerts when new articles cite this article - sign up in the box at the Service top right corner of the article or click here.

\section{Affordable, Accurate Sequencing.}

\section{gencove}

To subscribe to Genome Research go to: https://genome.cshlp.org/subscriptions 